\title{
DEUTSCHE ZEITSCHRIFT FÜR
}

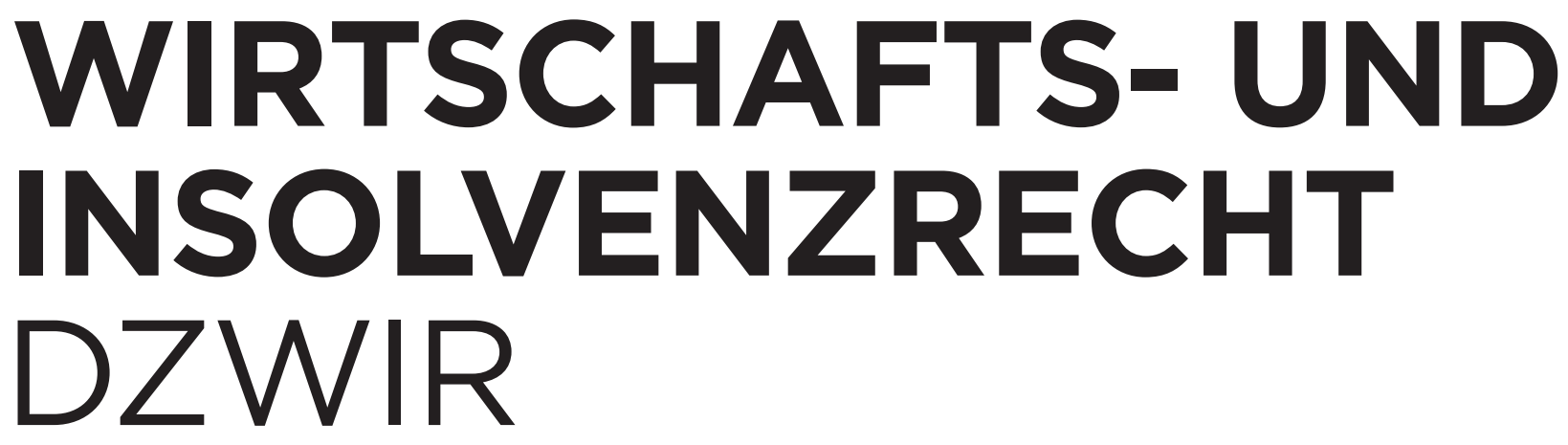

SCHRIFTLEITUNG

Michael Schmidt, Berlin 
Der Verlag hat für die Wiedergabe aller in dieser Zeitschrift enthaltenen Informationen (Programme, Verfahren, Mengen, Dosierungen, Applikationen etc.) mit Autoren und Herausgebern große Mühe darauf verwandt, diese Angaben genau entsprechend dem Wissensstand bei Fertigstellung des Werkes abzudrucken. Trotz sorgfältiger Herstellung des Manuskripts und Korrektur des Satzes können Fehler nicht ganz ausgeschlossen werden. Autoren bzw. Herausgeber und Verlag übernehmen infolgedessen keine Verantwortung und keine daraus folgende oder sonstige Haftung, die auf irgendeine Art aus der Benutzung der in dem Werk enthaltenen Informationen oder Teilen davon entsteht. Die Wiedergabe von Gebrauchsnamen, Handelsnamen,

Warenbezeichnungen und dergleichen in dieser Zeitschrift berechtigt nicht zu der Annahme, dass solche Namen ohne Weiteres von jedermann benutzt werden dürfen. Vielmehr handelt es sich häufig um gesetzlich geschützte, eingetragene Warenzeichen, auch wenn sie nicht eigens als solche gekennzeichnet sind.

ISSN 1439-1589 • e-ISSN 1612-7056

Alle Informationen zur Zeitschrift, wie Hinweise für Autoren, Open Access, Bezugsbedingungen und Bestellformulare, sind online zu finden unter www.degruyter.com/dzwir.

SCHRIFTLEITER Rechtsanwalt Michael Schmidt, Kurfürstendamm 171, D-10707 Berlin, Tel.: +49 (0)30 8857 90-0, Fax: +49 (0)30 8857 90-10, Email: m.schmidt@mac.com

JOURNAL MANAGER Jana Kuchta, De Gruyter, Genthiner Straße 13, 10785 Berlin, Germany, Tel.: +49 (0)30 260 05-2 28, Fax: +49 (0)30 260 05-2 50, Email: jana.kuchta@degruyter.com

ANZEIGENVERANTWORTLICHER Heiko Schulze, De Gruyter, Genthiner Straße 13, 10785 Berlin, Germany, Tel.: +49 (0)30 260 05-3 58, Email: anzeigen@degruyter.com

(C) 2016 Walter de Gruyter GmbH, Berlin/Boston

SATZ jürgen ullrich typosatz, Nördlingen

DRUCK Franz X. Stückle Druck und Verlag e.K., Ettenheim

Printed in Germany

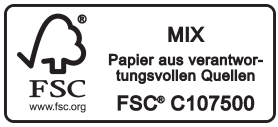




\section{Inhalt}

\section{Aufsatz}

Univ.-Prof. Dr. iur. utr. Christoph Becker

Arbeitnehmervorzug in der Krise? - 1

\section{Dokumentation}

BMF, Schreiben vom 18. 11. 2015 - IV A 3 -

S 0550/10/10020-05

Ergänzung des Schreibens vom 20. 5. 2015 zu den

Anwendungsfragen zu $§ 55$ Abs. 4 Ins $0-13$

\section{Rechtsprechung}

Europäische Gerichtsbarkeit

EuGH, Urteil vom 16. 4. 2015 - Rs. C-557/13 - Lutz Insolvenzanfechtung der nach Verfahrenseröffnung erfolgten Auszahlung eines vor Eröffnung gepfändeten Geldbetrages - 14

Finanzgerichtsbarkeit

BFH, Beschluss vom 1. 9. 2015 - VII B 178/14

Verjährungsunterbrechung durch Antrag auf Eröffnung des Insolvenzverfahrens -19

Zivilgerichtsbarkeit

BGH, Urteil vom 10. 7. 2014 - IX ZR 50/12

Vorsätzliche Benachteiligung bei einem Rechtsgeschäft unter Angehörigen - 20

BGH, Urteil vom 10. 7. 2014 - IX ZR 192/13

(Besprechung Univ.-Prof. Dr. iur. utr. Christoph Becker, S. 1)

Gehaltsforderung an einen Gesellschafter nach den Grundsätzen des Bargeschäfts — 23
BGH, Urteil vom 16. 4. 2015 - IX ZR 68/14

Indiz für Gläubigerbenachteiligungsvorsatz -29

Urteil vom 30. 6. 2015 - II ZR 142/14

Anmerkung Dr. iur. Philipp Böcker

Einberufung der Hauptversammlung einer Aktien-

gesellschaft -32

BGH, Beschluss vom 9. 7. 2015 - IX ZB 68/14

Rückwirkender Antrag auf Stundung der Insolvenz-

verfahrenskosten -43

BGH, Beschluss vom 24. 9. 2015 - IX ZR 308/14

Bitte um Ratenzahlungsvereinbarung nach fruchtlosen

Mahnungen - 46

BGH, Urteil vom 15. 10. 2015 - IX ZR 265/12 - LutZ

Insolvenzanfechtung der nach Verfahrenseröffnung erfolgten Auszahlung eines vor Eröffnung gepfändeten Geldbetrages - 47

\section{Buchbesprechung}

Prof. Dr. iur. Domenik Henning Wendt, LL.M.

Christoph Schmitt (Hrsg.), Praxishandbuch Gestaltung von Wirtschaftsverträgen, 1. Auflage - 50

\section{Veranstaltungen -51}

Nachrichten -52 
